\title{
Effect of supplemental vitamin D and calcium on serum sclerostin levels
}

\author{
Bess Dawson-Hughes ${ }^{1,2}$, Susan S Harris' ${ }^{1}$, Lisa Ceglia ${ }^{1,2}$ and Nancy J Palermo' \\ ${ }^{1}$ Jean Mayer United States Department of Agriculture Human Nutrition Research Center on Aging, Tufts University, \\ 711 Washington Street, Boston, Massachusetts 02111, USA and ${ }^{2}$ Division of Endocrinology, Diabetes and \\ Metabolism, Tufts Medical Center, Boston, Massachusetts 02111, USA
}

Correspondence should be addressed to B Dawson-Hughes Email Bess.Dawson-Hughes@ Tufts.edu

\begin{abstract}
Objective: Serum sclerostin levels have been reported to be inversely associated with serum 25OHD levels, but the effect of vitamin $\mathrm{D}$ and calcium supplementation on serum sclerostin levels is unknown. This study was carried out to determine whether vitamin $\mathrm{D}$ and calcium supplementation altered serum sclerostin levels in healthy older adults.

Design: We measured serum sclerostin levels at baseline and after 2 years in 279 men and women who participated in a placebo-controlled vitamin D (700 IU/day) and calcium ( $500 \mathrm{mg} /$ day) intervention trial carried out in men and women aged $\geq 65$ years.

Method: Serum sclerostin levels were measured using the MesoScale Discovery chemiluminescence assay.

Results: In the men, sclerostin levels increased over 2 years by $4.11 \pm 1.81 \mathrm{ng} / \mathrm{l}(13.1 \%)$ in the vitamin D plus calciumsupplemented group and decreased by $3.16 \pm 1.78 \mathrm{ng} / \mathrm{l}(10.9 \%)$ in the placebo group ( $P=0.005$ for difference in change). Adjustments for the season of measurement, baseline physical activity levels, baseline serum sclerostin levels, and total body bone mineral content did not substantially alter the changes. In the women, there was no significant group difference in change in serum sclerostin levels either before or after the above-mentioned adjustments. In both the sexes, vitamin $D$ and calcium supplementation significantly increased serum ionized calcium levels and decreased parathyroid hormone levels. Conclusion: Men and women appear to have different serum sclerostin responses to vitamin $\mathrm{D}$ and calcium supplementation. The reason for this difference remains to be determined.
\end{abstract}

\section{Introduction}

Sclerostin is a glycoprotein produced by osteocytes that is being evaluated as a potential clinical marker of bone turnover. A recent report has identified an inverse association between serum 25OHD and sclerostin levels in healthy postmenopausal women (1). Vitamin D and calcium supplementation may influence circulating sclerostin levels due to several reasons. Supplementation with these nutrients decreases serum parathyroid hormone (PTH) levels (2), and PTH is a negative regulator of sclerostin expression $(3,4)$. Hence, a decline in PTH levels should increase serum sclerostin levels. Sclerostin is known as an inhibitor of bone formation, and several cross-sectional studies have identified inverse associations of serum sclerostin levels with a variety of biochemical (c) 2014 European Society of Endocrinology Printed in Great Britain markers of bone turnover $(5,6,7)$, although this has not been a consistent finding in men and women (6). Vitamin $\mathrm{D}$ and calcium supplementation lowers the levels of other bone turnover markers by up to $10 \%$, but whether it alters serum sclerostin levels has not been examined.

It is important to understand the determinants of serum sclerostin levels to gain insights into the regulation of osteocyte function. Toward this end, in this study, we examined whether treatment with calcium and vitamin $\mathrm{D}_{3}$ for 2 years, when compared with placebo, altered serum sclerostin levels in healthy men and women aged $\geq 65$ years. We also examined, at baseline, the associations of serum sclerostin levels with bone mineral density (BMD), total body bone mineral content (BMC), and the 
biochemical marker of bone formation, serum osteocalcin. The subjects of this study participated in STOP/IT, a randomized trial in which supplementation with calcium (500 mg) plus vitamin $\mathrm{D}_{3}$ (700 IU/day), when compared with placebo, lowered serum PTH levels, improved BMD, and lowered fracture rates (2).

\section{Subjects and methods}

This study was carried out using existing data and new sclerostin measurements in serum archived at baseline and 2 years from healthy men and women aged $\geq 65$ years who participated in our STOP/IT calcium and vitamin D intervention trial (Clinical Trial: NCT00357643) (2). Of the 389 subjects who completed the trial, we excluded 21 subjects with diabetes because they have been reported to have higher sclerostin levels $(8,9), 14$ non-white subjects because they had different PTH homeostasis (10), and subjects with no stored serum samples $(n=40)$. The remaining 314 subjects had data on sclerostin measurements at baseline available and, of these, 279 had samples available and these were measured at 2 years.

The subjects were enrolled from February 1992 to February 1993. The study was approved by the Tufts Medical Center Human Investigation Review Committee, and all participants gave written informed consent. Criteria for exclusion included use of calcium or vitamin D supplements for 2 months prior to enrollment, bonealtering conditions or medications, kidney or liver disease, and current cancer (see (2) for a detailed list).

Blood samples were collected between 0700 and $0900 \mathrm{~h}$ after the subjects had fasted for at least $8 \mathrm{~h}$. During the trial, serum osteocalcin levels were measured by IRMA (Nichols Institute, San Juan Capistrano, CA, USA), PTH levels by immunometric assay (Nichols Institute), and serum 25OHD levels by the method of Preece et al. (11) with coefficient of variation $(\mathrm{CV})$ values ranging from 5.6 to $7.7 \%$. Serum estradiol $\left(\mathrm{E}_{2}\right)$ levels were measured by RIA following solvent extraction and Celite chromatography, with CV values of 7.0 and $13.2 \%$. Total testosterone levels were measured using RIA kits from Diagnostic Products Corp. (Los Angeles, CA, USA) with CV values of 5.9 and $8.7 \%$. Serum creatinine levels were measured by colorimetry using the Cobas Fara centrifugal analyzer (Roche Instruments). Urinary creatinine levels were measured by direct-current plasma emission spectroscopy with Spectrascan 6 (Beckman Instruments, Palo Alto, CA, USA) and serum ionized calcium levels with the Nova 7 analyzer (Nova Biomedical, Newton, MA, USA). Serum sclerostin levels were batch analyzed in 2013 in serum archived at $-80^{\circ} \mathrm{C}$ and not previously thawed. The samples were assayed on MesoScale Discovery (Rockville, MD, USA), utilizing a proprietary combination of electrochemiluminescence detection and patterned arrays. This assay detects only intact sclerostin in the serum (5). The reference range for this assay is $18-156 \mathrm{ng} / \mathrm{l}$, the mean $\mathrm{CV}$ of this assay is $4 \%$, and the lower level of detection (defined as 2.5 s.D. above the background) is $1.1 \mathrm{ng} / 1$.

BMD of the spine, femoral neck, and total body and total body BMC were measured by dual-energy X-ray absorptiometry (DXA) using a DPX-L scanner (Lunar Radiation, Madison, WI, USA) with CV values of $1.0 \%$ (spine), 1.7\% (femoral neck), and $0.7 \%$ (total body BMD) and $1.2 \%$ (total body BMC) (12).

Leisure, household, and occupational activity levels were estimated using the Physical Activity Scale for the Elderly (PASE) questionnaire (13).

Analyses were conducted with SPSS, version 21.0 (IBM Corp., Armonk, NY, USA). Preliminary analyses indicated that sex modified the effect of treatment on changes in sclerostin levels (test for interaction, $P=0.003$ ). For this reason, the final analyses were conducted separately in men and women. Baseline characteristics were compared across the treatment groups with $t$-tests for two independent samples. Mean sclerostin values at baseline, adjusted for the season of measurement, were computed with the LSMeans option in the general linear model procedure and compared across the sex-specific tertiles of related variables. The same method was used to compute mean changes in sclerostin values, adjusted for covariates, and compare them across the treatment groups. $P$ values $<0.05$ were considered to indicate statistical significance.

\section{Results}

At baseline, mean serum sclerostin levels were $30.1 \pm 18.2$ (s.D.) $\mathrm{ng} / \mathrm{l}$ in the men and $28.1 \pm 14.3 \mathrm{ng} / \mathrm{l}$ in the women $(P$ for difference $=0.290)$; mean PASE scores were $129 \pm 57$ in the men and $106 \pm 50$ in the women $(P<0.001)$. The clinical characteristics of the 314 participants, by gender and treatment group, are summarized in Table 1. There were no significant treatment group differences in serum sclerostin levels in either the men or the women.

Over the 2 years of treatment, in the men, serum sclerostin levels increased by $4.11 \pm 1.81$ (s.E.M.) $\mathrm{ng} / \mathrm{l}(13.1 \%)$ in the vitamin D plus calcium-supplemented group and decreased by $3.16 \pm 1.78 \mathrm{ng} / \mathrm{l}(10.9 \%)$ in the placebo group ( $P$ for group difference $<0.005$, Table 2 ). Adjustments for baseline sclerostin levels, season of measurement, and PASE score, all significant predictors of change in sclerostin levels, 
Table 1 Characteristics of the 314 subjects at baseline by gender and treatment group \pm s.D.

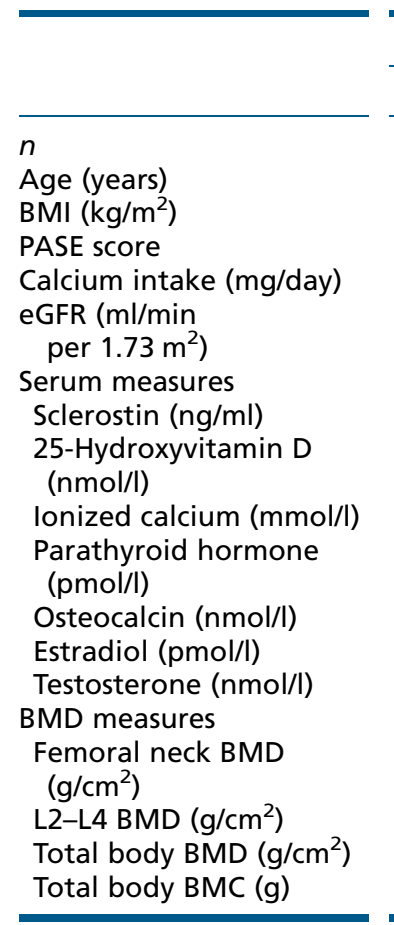

\begin{tabular}{|c|c|c|}
\hline \multicolumn{3}{|c|}{ Men } \\
\hline Placebo & Calcium + vitamin D & $P$ \\
\hline 67 & 66 & \\
\hline $71.2 \pm 5.1$ & $70.6 \pm 4.5$ & 0.475 \\
\hline $27.0 \pm 3.2$ & $26.9 \pm 3.0$ & 0.760 \\
\hline $125.9 \pm 56.9(66)$ & $132.3 \pm 56.6(65)$ & 0.519 \\
\hline $700.6 \pm 382.0$ & $750.0 \pm 411.1$ & 0.474 \\
\hline $74.8 \pm 14.8$ & $79.9 \pm 15.1$ & 0.050 \\
\hline $28.9 \pm 11.4$ & $31.3 \pm 23.2$ & 0.450 \\
\hline $88.9 \pm 30.0$ & $84.9 \pm 40.8$ & 0.516 \\
\hline $2.51 \pm 0.07(66)$ & $2.51 \pm 0.08$ & 0.526 \\
\hline $3.61 \pm 1.37$ & $4.09 \pm 2.06$ & 0.122 \\
\hline $1.01 \pm 0.34$ & $0.93 \pm 0.23$ & 0.131 \\
\hline $99.4 \pm 38.8(63)$ & $106.5 \pm 44.5(64)$ & 0.336 \\
\hline $16.6 \pm 4.8(62)$ & $17.5 \pm 4.8(63)$ & 0.302 \\
\hline $0.94 \pm 0.11$ & $0.98 \pm 0.14$ & 0.033 \\
\hline $1.26 \pm 0.19(66)$ & $1.33 \pm 0.20(65)$ & 0.053 \\
\hline $1.19 \pm 0.08(66)$ & $1.21 \pm 0.09$ & 0.159 \\
\hline $2937 \pm 404(66)$ & $2990 \pm 346$ & 0.426 \\
\hline
\end{tabular}

\begin{tabular}{|c|c|c|}
\hline \multicolumn{3}{|c|}{ Women } \\
\hline Placebo & Calcium + vitamin D & $P$ \\
\hline 95 & 86 & \\
\hline $71.9 \pm 4.6$ & $70.9 \pm 4.3$ & 0.143 \\
\hline $26.5 \pm 4.7$ & $26.3 \pm 3.9$ & 0.742 \\
\hline $108.5 \pm 53.0$ & $104.8 \pm 45.9$ & 0.535 \\
\hline $801.0 \pm 349.0$ & $678.1 \pm 281.4$ & 0.010 \\
\hline $73.8 \pm 11.9$ & $76.3 \pm 14.1$ & 0.202 \\
\hline $27.8 \pm 14.1$ & $28.5 \pm 14.5$ & 0.726 \\
\hline $63.3 \pm 7.5$ & $73.3 \pm 33.7$ & 0.030 \\
\hline $2.52 \pm 0.08$ & $2.55 \pm 0.07$ & 0.034 \\
\hline $4.45 \pm 1.96$ & $3.88 \pm 1.40$ & 0.027 \\
\hline $1.25 \pm 0.41$ & $1.19 \pm 0.38$ & 0.309 \\
\hline $93.0 \pm 54.1(90)$ & $94.4 \pm 68.0(83)$ & 0.878 \\
\hline $1.3 \pm 0.9(89)$ & $1.4 \pm 1.1(83)$ & 0.782 \\
\hline $0.80 \pm 0.10$ & $0.80 \pm 0.11$ & 0.609 \\
\hline $1.03 \pm 0.20$ & $1.03 \pm 0.19(79)$ & 0.913 \\
\hline $1.01 \pm 0.09$ & $1.01 \pm 0.09$ & 0.921 \\
\hline $1910 \pm 292$ & $1894 \pm 286$ & 0.709 \\
\hline
\end{tabular}

did not substantially alter the effect of supplementation on changes in serum sclerostin levels (Table 2). Additional adjustment for total body BMC similarly did not change the finding (Table 2). In the women, serum sclerostin levels decreased by $3.55 \pm 1.50 \mathrm{ng} / 1(12.5 \%)$ in the vitamin D plus calcium-supplemented group and decreased by $1.02 \pm 1.40 \mathrm{ng} / \mathrm{l}(3.7 \%)$ in the placebo group, but the group difference was not statistically significant either before or after the same adjustments (Table 2). The levels of gonadal hormones, $\mathrm{E}_{2}$ and testosterone, were not significantly correlated with serum sclerostin levels at baseline, and they were not significant predictors of change in serum sclerostin levels, and they did not modify the effect of supplementation on changes in serum sclerostin levels in the men or the women. As expected, vitamin D and calcium supplementation significantly increased serum ionized calcium levels and lowered serum PTH and osteocalcin levels in the men and women (Table 2).

At baseline, serum sclerostin levels did not differ across the tertiles of serum $25 \mathrm{OHD}$ values in the men or

Table 2 Mean ( \pm s.Е.м.) 2-year changes in serum sclerostin levels by gender and treatment group in 279 subjects.

\begin{tabular}{|c|c|c|c|c|c|c|}
\hline & \multicolumn{3}{|c|}{ Men } & \multicolumn{3}{|c|}{ Women } \\
\hline & Placebo & Calcium + vitamin D & $P$ & Placebo & Calcium + vitamin D & $P$ \\
\hline$n$ & 62 & 60 & & 84 & 73 & \\
\hline \multicolumn{7}{|c|}{ Change in sclerostin levels (ng/l) } \\
\hline Unadjusted & $-3.16 \pm 1.78$ & $4.11 \pm 1.81$ & 0.005 & $-1.02 \pm 1.40$ & $-3.55 \pm 1.50$ & 0.217 \\
\hline Adjusted $^{a}$ & $-3.85 \pm 1.64$ & $3.99 \pm 1.70$ & 0.001 & $-0.99 \pm 1.17$ & $-3.23 \pm 1.25$ & 0.186 \\
\hline Adjusted $^{\mathrm{b}}$ & $-3.78 \pm 1.67$ & $3.98 \pm 1.71$ & 0.001 & $-0.97 \pm 1.18$ & $-3.23 \pm 1.25$ & 0.184 \\
\hline \multicolumn{7}{|c|}{ Change in ionized calcium levels ( $\mathrm{mmol} / \mathrm{l})$} \\
\hline Unadjusted & $0.04 \pm 0.01^{c}$ & $0.09 \pm 0.01$ & 0.001 & $0.03 \pm 0.01$ & $0.09 \pm 0.01$ & $<0.001$ \\
\hline \multicolumn{7}{|c|}{ Change in PTH levels (pmol/l) } \\
\hline Unadjusted & $0.65 \pm 0.16$ & $-0.88 \pm 0.21$ & $<0.001$ & $0.88 \pm 0.22$ & $-0.81 \pm 0.14$ & $<0.001$ \\
\hline \multicolumn{7}{|c|}{ Change in osteocalcin levels (nmol/l) } \\
\hline Unadjusted & $0.03 \pm 0.03$ & $-0.14 \pm 0.02$ & $<0.001$ & $-0.06 \pm 0.03$ & $-0.25 \pm 0.03$ & $<0.001$ \\
\hline
\end{tabular}


Table 3 Mean ( \pm S.E.M.) baseline serum sclerostin levels, adjusted for the season of measurement, by tertile of the selected variables in 314 subjects.

\begin{tabular}{|c|c|c|c|c|c|}
\hline \multicolumn{3}{|c|}{ Men } & \multicolumn{3}{|c|}{ Women } \\
\hline Tertile boundaries & Sclerostin (ng/l) & $P$ & Tertile boundaries & Sclerostin (ng/l) & $P$ \\
\hline \multicolumn{6}{|c|}{ 25-Hydroxyvitamin D (nmol/l) } \\
\hline$<69.9$ & $26.8 \pm 2.9$ & 0.420 & $<52.4$ & $25.8 \pm 1.8$ & 0.690 \\
\hline 69.9-97.3 & $31.6 \pm 3.0$ & & $52.4-74.8$ & $27.7 \pm 1.9$ & \\
\hline$\geq 97.4$ & $31.4 \pm 2.7$ & & $\geq 74.9$ & $27.7 \pm 1.7$ & \\
\hline \multicolumn{6}{|l|}{ PTH (pmol/l) } \\
\hline$<2.9$ & $31.7 \pm 2.7$ & 0.445 & $<3.3$ & $25.4 \pm 1.8$ & 0.556 \\
\hline $2.9-4.2$ & $31.0 \pm 2.8$ & & $3.3-4.4$ & $27.7 \pm 1.7$ & \\
\hline$\geq 4.3$ & $27.2 \pm 2.7$ & & $\geq 4.5$ & $27.9 \pm 1.7$ & \\
\hline \multicolumn{6}{|c|}{ Serum osteocalcin (nmol/l) } \\
\hline$<0.8$ & $26.9 \pm 2.6$ & 0.008 & $<1.0$ & $25.4 \pm 1.7$ & 0.249 \\
\hline $0.8-1.0$ & $26.3 \pm 2.7$ & & $1.0-1.3$ & $29.3 \pm 1.7$ & \\
\hline$\geq 1.1$ & $36.9 \pm 2.7^{*}$ & & $\geq 1.4$ & $26.5 \pm 1.7$ & \\
\hline \multicolumn{6}{|c|}{ Bone mineral density $\left(\mathrm{g} / \mathrm{cm}^{2}\right)$} \\
\hline \multicolumn{6}{|c|}{ Femoral neck } \\
\hline$<0.90$ & $28.2 \pm 2.9$ & 0.712 & $<0.75$ & $29.4 \pm 1.8$ & 0.108 \\
\hline $0.90-1.00$ & $29.9 \pm 2.6$ & & $0.75-0.83$ & $24.4 \pm 1.7$ & \\
\hline$\geq 1.01$ & $31.5 \pm 2.7$ & & $\geq 0.84$ & $27.7 \pm 1.7$ & \\
\hline \multicolumn{6}{|l|}{ L2-L4 spine } \\
\hline$<1.20$ & $29.3 \pm 2.8$ & 0.673 & $<0.93$ & $28.5 \pm 1.8$ & 0.667 \\
\hline $1.20-1.36$ & $28.7 \pm 2.8$ & & $0.93-1.08$ & $26.2 \pm 1.8$ & \\
\hline$\geq 1.37$ & $32.1 \pm 2.9$ & & $\geq 1.09$ & $27.7 \pm 1.8$ & \\
\hline \multicolumn{6}{|l|}{ Total body } \\
\hline$<1.16$ & $26.6 \pm 2.7$ & 0.231 & $<0.97$ & $27.5 \pm 1.8$ & 0.939 \\
\hline $1.16-1.23$ & $30.3 \pm 2.7$ & & $0.97-1.05$ & $27.2 \pm 1.7$ & \\
\hline$\geq 1.24$ & $33.2 \pm 2.8$ & & $\geq 1.06$ & $26.6 \pm 1.7$ & \\
\hline \multicolumn{6}{|c|}{ Bone mineral content (g) } \\
\hline \multicolumn{6}{|c|}{ Total body } \\
\hline$<2774$ & $28.6 \pm 2.7$ & 0.437 & $<1770$ & $27.1 \pm 1.8$ & 0.749 \\
\hline 2774-3116 & $28.5 \pm 2.8$ & & 1770-2041 & $28.0 \pm 1.7$ & \\
\hline$\geq 3117$ & $32.9 \pm 2.8$ & & $\geq 2042$ & $26.1 \pm 1.7$ & \\
\hline
\end{tabular}

the women. In the men, serum sclerostin levels were higher in the highest tertile of serum osteocalcin values than in the lower two tertiles $(P=0.008$ for both comparisons; Table 3). In the women, serum sclerostin levels did not differ significantly across the tertiles of serum osteocalcin values. Baseline serum sclerostin levels did not differ across the tertiles of serum PTH values before or after adjustment for total body BMC in the men or the women. Similarly, serum sclerostin levels did not differ across the tertiles of BMD values at any skeletal site or BMC of the total body (Table 3).

There were no significant associations between 2-year change in serum sclerostin levels and 2-year change in $\mathrm{BMD}$ at any site or change in total body BMC.

\section{Discussion}

In this large randomized controlled trial, treatment with vitamin $\mathrm{D}$ and calcium, when compared with placebo, increased serum sclerostin levels in the men. This increase was compatible with the observed declines in PTH and osteocalcin levels that occurred on using the supplements. Surprisingly, the same pattern was not observed in the women. On using the supplements, serum sclerostin levels in the women did not increase, and in fact declined, although not significantly, despite declines in serum PTH and osteocalcin levels that were similar to those observed in the men. In contrast to the observed sex difference in change in sclerostin levels, sex did not modify the effect of calcium and vitamin D supplementation on changes in BMD (2). The reason for the divergent sclerostin responses to supplementation in the men and women is not clear. It is possible that their higher basal levels of physical activity may have sensitized the men and enhanced their sclerostin response to the supplements. There is precedent for divergent sclerostin findings in different sexes and in populations with different basal levels of physical activity. Fazeli et al. (14) have recently observed that among 
eumenorrheic young women, serum sclerostin levels are positively associated with spinal BMD in athletic women but inversely associated in the non-athletic women. We have recently observed seasonal variation in serum sclerostin levels (15), but our findings were adjusted for season; they were also adjusted for physical activity levels.

In the analyses of baseline data, we found no association of serum sclerostin levels with BMD at any site or with total body BMC. This is in contrast to the findings of Durosier et al. (5), who, using the same sclerostin assay, reported a positive association of sclerostin levels with BMD at several sites in a similar older population. It is also in contrast to the findings of Szulc et al. (16), who reported that higher serum sclerostin levels are associated with lower bone turnover rate, higher BMD, and lower risk of fracture. Modder et al. (6), using the Biomedica assay, identified a positive correlation between serum sclerostin levels and total body BMC and also found positive correlations between serum sclerostin levels and BMD of the spine, hip, and total body in a random sample of healthy older men and women. This finding has been confirmed in healthy postmenopausal women (17) and in a small group of adults with type 2 diabetes (8).

In the men, sclerostin levels at baseline were positively associated with serum osteocalcin levels, but the association was not linear. Higher sclerostin levels were observed in the top tertile of osteocalcin values but not in the lower two tertiles. No association was found in the women. Modder et al. (6) did not find significant associations of serum sclerostin levels with osteocalcin levels in older men or women, but did observe significant inverse associations of sclerostin levels with several biochemical markers of bone resorption in men, although not in women. Durosier et al. (5) observed a significant inverse association of serum sclerostin levels with serum P1NP and CTX levels in a combined group of older men and women, as did Garnero et al. (17) in postmenopausal women. Thus, findings linking serum sclerostin levels to biochemical markers of bone turnover in older adults are somewhat variable across study populations for reasons that are unclear.

A factor that is undoubtedly adding to the divergence and inconsistency in findings related to serum sclerostin is that available assays measure different components of the sclerostin molecule. As elegantly described by Durosier et al. (5), the MesoScale Discovery, the assay used in the present study, appears to detect only the intact sclerostin molecule, whereas the other commonly used assays detect various circulating fragments as well as intact sclerostin. The reference range for the MesoScale assay is 30-fold lower than that for other assays (5). The sclerostin values obtained in the present study were similar to those measured in samples collected recently from older men and women and analyzed by the same method (5). Samples from the Study of Osteoporotic Fractures that had been stored for about 20 years have also yielded sclerostin values in the expected range (18). These findings suggest that serum sclerostin is stable for an extended period when stored at $-80^{\circ} \mathrm{C}$ and not exposed to thawing and refreezing.

Another potential source of inconsistency in observations may be that not all studies have adjusted for a surrogate of osteocyte pool size such as total body BMC. It has been proposed that sclerostin in the circulation may be influenced by the osteocyte pool size $(5,6,17)$, which should be proportional to total body BMC. Durosier et al. (5) estimated that $17 \%$ of the variability in circulating sclerostin levels is determined by the osteocyte pool size, as measured by total body BMC DXA. However, unlike Durosier et al., we found no association of serum sclerostin levels with total body BMC. Finally, associations of sclerostin levels with bone turnover may vary with age, sex, circulating testosterone or estrogen levels, and usual levels of physical activity. Until the influence of these and other factors on sclerostin is better understood, findings related to this measure should be interpreted with caution.

In conclusion, we observed that treatment with vitamin D and calcium increased serum sclerostin levels in healthy older men but not in women. Similarly, baseline sclerostin and osteocalcin levels were positively associated in the men but not in the women. These observations contribute to scattered findings reported in other data sets and, in themselves, do not indicate much clinical utility of serum sclerostin measurements as indicators of bone turnover at present.

\section{Declaration of interest}

The authors declare that there is no conflict of interest that could be perceived as prejudicing the impartiality of the research reported. The authors have full control of all primary data and agree to allow the journal to review the data if requested.

\section{Funding}

This study was supported by grant number AG10353 from the U.S. National Institute on Aging and the National Institutes of Health, Amgen, Inc., and the U.S. Department of Agriculture, Agricultural Research Service, under agreement no. 58-1950-0-014. Any opinions, findings, conclusion, or recommendations expressed in this publication are those of the author(s) and do not necessarily reflect the view of the U.S. Department of Agriculture. 


\section{Author contribution statement}

B Dawson-Hughes and S S Harris designed and implemented the trial; B Dawson-Hughes, S S Harris, and L Ceglia designed and implemented the sclerostin component; S S Harris and N J Palermo contributed to data management and data analyses, and all authors were involved in the preparation of the manuscript.

\section{References}

1 Ardawi MS, Al-Kadi HA, Rouzi AA \& Qari MH. Determinants of serum sclerostin in healthy pre- and postmenopausal women. Journal of Bone and Mineral Research 201126 2812-2822. (doi:10.1002/jbmr.479)

2 Dawson-Hughes B, Harris SS, Krall EA \& Dallal GE. Effect of calcium and vitamin D supplementation on bone density in men and women 65 years of age or older. New England Journal of Medicine 1997337 670-676. (doi:10.1056/NEJM199709043371003)

3 Bellido T, Ali AA, Gubrij I, Plotkin LI, Fu Q, O'Brien CA, Manolagas SC \& Jilka RL. Chronic elevation of parathyroid hormone in mice reduces expression of sclerostin by osteocytes: a novel mechanism for hormonal control of osteoblastogenesis. Endocrinology 2005146 4577-4583. (doi:10.1210/en.2005-0239)

4 Drake MT, Srinivasan B, Modder UI, Peterson JM, McCready LK, Riggs BL, Dwyer D, Stolina M, Kostenuik P \& Khosl S. Effects of parathyroid hormone treatment on circulating sclerostin levels in postmenopausal women. Journal of Clinical Endocrinology and Metabolism 201095 5056-5062. (doi:10.1210/jc.2010-0720)

5 Durosier C, Van Lierop A, Ferrari S, Chevalley T, Papapoulos S \& Rizzoli R. Association of circulating sclerostin with bone mineral mass, microstructure, and turnover biochemical markers in healthy elderly men and women. Journal of Clinical Endocrinology and Metabolism 2013 98 3873-3883. (doi:10.1210/jc.2013-2113)

6 Modder UI, Hoey KA, Amin S, McCready LK, Achenbach SJ, Riggs BL, Melton LJ III \& Khosla S. Relation of age gender, and bone mass to circulating sclerostin levels in women and men. Journal of Bone and Mineral Research 201126 373-379. (doi:10.1002/jbmr.217)

7 Krishnan V, Bryant HU \& Macdougald OA. Regulation of bone mass by Wnt signaling. Journal of Clinical Investigation 2006116 1202-1209. (doi:10.1172/JCI28551)

8 Garcia-Martin A, Rozas-Moreno P, Reyes-Garcia R, Morales-Santana S, Garcia-Fontana B, Garcia-Salcedo JA \& Muno Torres M. Circulating levels of sclerostin are increased in patients with type 2 diabetes mellitus. Journal of Clinical Endocrinology and Metabolism 201297 234-241. (doi:10.1210/jc.2011-2186)

9 Gennari L, Merlotti D, Valenti R, Ceccarelli E, Ruvio M, Pietrini MG, Capodarca C, Franci MB, Campagna MS, Calabro A et al. Circulating sclerostin levels and bone turnover in type 1 and type 2 diabetes. Journal of Clinical Endocrinology and Metabolism 201297 1737-1744. (doi:10.1210/jc.2011-2958)

10 Fuleihan GE, Gundberg CM, Gleason R, Brown EM, Stromski ME, Grant FD \& Conlin PR. Racial differences in parathyroid hormone dynamics. Journal of Clinical Endocrinology and Metabolism 199479 1642-1647. (doi:10.1210/jcem.79.6.7989469)

11 Preece MA, O’Riordan JL, Lawson DE \& Kodicek E. A competitive protein-binding assay for 25-hydroxycholecalciferol and 25-hydroxyergocalciferol in serum. Clinica Chimica Acta 197454 235-242. (doi:10.1016/0009-8981(74)90241-1)

12 White J, Harris SS, Dallal GE \& Dawson-Hughes B. Precision of single vs bilateral hip bone mineral density scans. Journal of Clinical Densitometry 20036 159-162. (doi:10.1385/JCD:6:2:159)

13 Washburn RA, Smith KW, Jette AM \& Janney CA. The Physical Activity Scale for the Elderly (PASE): development an evaluation. Journal of Clinical Epidemiology 199346 153-162. (doi:10.1016/08954356(93)90053-4)

14 Fazeli PK, Ackerman KE, Pierce L, Guereca G, Bouxsein M \& Misra M. Sclerostin and Pref- 1 have differential effects on bone mineral density and strength parameters in adolescent athletes compared with non-athletes. Osteoporosis International 201324 2433-2440. (doi:10.1007/s00198-013-2353-2)

15 Dawson-Hughes B, Harris SS, Ceglia L \& Palermo NJ. Serum sclerostin levels vary with season. Journal of Clinical Endocrinology and Metabolism 201399 E149-E152. (doi:10.1210/jc.2013-3148)

16 Szulc P, Bertholon C, Borel O, Marchand F \& Chapurlat R. Lower fracture risk in older men with higher sclerostin concentration: a prospective analysis from the MINOS study. Journal of Bone and Mineral Research 201328 855-864. (doi:10.1002/jbmr.1823)

17 Garnero P, Sornay-Rendu E, Munoz F, Borel O \& Chapurlat RD. Association of serum sclerostin with bone mineral density bone turnover, steroid and parathyroid hormones, and fracture risk in postmenopausal women: the OFELY study. Osteoporosis International 201324 489-494. (doi:10.1007/s00198-012-1978-x)

18 Arasu A, Cawthon PM, Lui LY, Do TP, Arora PS, Cauley JA, Ensrud KE \& Cummings SR. Serum sclerostin and risk of hip fracture in older Caucasian women. Journal of Clinical Endocrinology and Metabolism 2012 97 2027-2032. (doi:10.1210/jc.2011-3419)

Received 24 October 2013

Revised version received 9 December 2013

Accepted 31 January 2014 